\title{
Enquadramento estratégico das águas pluviais: a necessidade de uma gestão sustentável
}

\author{
Diogo Arezes*, Hélder Costa, Paulo J. Ramísio \\ Universidade do Minho, Campus de Azurém, 4800-058 Guimarães, Portugal
}

\section{Resumo}

A gestão das águas pluviais está diretamente relacionada com o desenvolvimento sustentável, apresentando um importante impacto na qualidade de vida dos centros urbanos. Apesar de alguns países liderarem um movimento para a definição de normas legais específicas e soluções integradas de gestão, em Portugal e na maior parte dos países, esta temática ainda se encontra numa fase bastante incipiente. Nesse sentido, este artigo apresenta e analisa os principais meios legisladores e instrumentos de gestão das águas pluviais existentes nos Estados Unidos da América e na União Europeia. Tem como objetivo expor as suas principais características e diferenças, assim como identificar as oportunidades resultantes da aplicação de uma gestão mais eficiente deste recurso. Esta revisão bibliográfica mostra que, ao contrário do que se verifica nos Estados Unidos da América, tanto na União Europeia como a nível nacional, não existem estratégias que estejam alinhadas com a importância e os efeitos dos sistemas de drenagem de águas pluviais. Pretende-se, assim, identificar aspetos centrais de atuação que contribuam para o desenvolvimento de estratégias promotoras de uma gestão mais sustentável deste recurso.

Palavras-Chave: águas pluviais, gestão de água, legislação da água, desenvolvimento sustentável.

doï: 10.22181/aer.2019.0503

* Autor para correspondência

E-mail: Idaarezes@gmail.com 


\title{
Stormwater strategic framework: the need for a sustainable management
}

\author{
Diogo Arezes*, Hélder Costa, Paulo J. Ramísio \\ Universidade do Minho, Campus de Azurém, 4800-058 Guimarães, Portugal
}

\begin{abstract}
Stormwater management is directly related to sustainable development, with a clear impact on the quality of life of urban centres. While some countries have, already, become aware of its importance, producing legislation and implementing management solutions, in other regions the approach to the problem is still in a very early stage. Therefore, in this article, an analysis of the legislation in the United States of America and in the European Union is made as far as stormwater is concerned. It aims to present the main characteristics and differences, as well as the great opportunities inherent to a more efficient management of this resource. This study has shown that, unlike in the United States of America, both in the European Union and at the national level, there is no legislation supporting the importance of stormwater. It is intended to alert and identify key aspects that contribute to the development of strategies focused on promoting a more sustainable management of this resource.
\end{abstract}

Keywords: stormwater, water management, water legislation, sustainable development.

doil: 10.22181/aer.2019.0503

* Corresponding author

E-mail: Idaarezes@gmail.com 


\section{Introdução}

A gestão da água assume um papel de enorme relevância na sociedade atual. Esta é uma preocupação antiga havendo registos de sistemas já bastante avançados em civilizações como na Grécia Antiga ou no Império da Mesopotâmia (Burian et al. 1999). A gestão tradicional da água urbana envolve a prestação de serviços de abastecimento de água e de drenagem de águas residuais através de uma rede de tubos enterrados e de canais abertos (Marlow et al. 2013). No entanto, fruto das alterações climáticas, do crescimento populacional e dos novos padrões migratórios, associados, na grande maioria das vezes, a um crescimento urbano deficiente e ao desenvolvimento de práticas agrícolas e industriais insustentáveis, o modelo clássico de gestão está seriamente ameaçado (Howden et al. 2007).

Com o desenvolvimento da engenharia associado ao crescimento urbano acelerado registado no séc. XIX, foram implementados sistemas de drenagem unitários em grandes cidades, contemplando conjuntamente a drenagem das águas residuais e das águas pluviais. Apresentando custos económicos bastante competitivos, este tipo de sistemas tem como grande problema o facto de apresentar aumentos significativos do caudal em situações de precipitação intensa. Este problema, aliás, tem sido discutido desde os anos 70 , onde as vantagens e desvantagens dos sistemas unitários comparativamente aos sistemas separativos têm sido demonstradas (Tarr 1979).

Nas últimas décadas, as infraestruturas e os centros urbanos sofreram profundas transformações, tendo-se desenvolvido em diferentes níveis de complexidade, levando a um aumentando da exigência no que diz respeito aos níveis de qualidade e de saúde pública (Barbosa et al. 2012). Por outro lado, a crescente impermeabilização dos solos nas cidades tem feito com que as escorrências decorrentes de eventos de precipitação apresentem picos de caudal mais elevados e tempos de concentração mais reduzidos (Jha et al. 2012). Ora não estando os sistemas de drenagem dimensionados para estes caudais tem-se verificado o surgimento, cada vez mais frequente, de cheias e inundações (Meehl et al. 2007).

Verifica-se ainda que, apesar do enorme avanço verificado nas políticas e na gestão dos sistemas de águas de abastecimento e nas águas residuais, e dos importantes impactos que estes apresentam na vida das populações, os processos associados à gestão de águas pluviais não acompanharam esta evolução (Gasperi et al. 2012).

Problemas decorrentes de uma maior poluição e consequente escassez de água potável levaram as Nações Unidas a prever um défice mundial de água potável de $40 \%$ até 2030 (UN WWA Programme 2015). Este défice tem originado uma crescente preocupação por parte da sociedade em geral (Kummu et al. 2016). Em alguns países, passou-se a adotar um novo paradigma baseado numa Gestão Integrada de Recursos Hídricos, assente numa visão holística de todos os tipos de água e tendo sempre em consideração a componente económica, social e ambiental (WWC 2015).

Por outro lado, na agenda do programa Europa 2020, produzido pela União Europeia, e no qual se definem as suas prioridades e objetivos estratégicos, é também dada especial relevância à água como recurso escasso (CE 2013). Esta é uma preocupação também verificada em Portugal ainda que de forma menos sentida no que às águas pluviais diz respeito, sendo estas, muitas vezes, encaminhadas diretamente para redes de drenagem de águas residuais ou para os cursos de água mais próximos, gerando impactos significativos no ambiente (Ramísio 2007).

Paralelamente, existem múltiplos países com políticas estratégicas transversais a todos os tipos de água e que contribuem, de uma forma bastante vincada, para a sustentabilidade global deste recurso. Os Estados Unidos da América, a Austrália e o 
Chile são bons exemplos disso mesmo, tendo vindo a desenvolver sólidos instrumentos de gestão nesta área.

Desta forma, neste artigo pretende-se avaliar o enquadramento estratégico da gestão das águas pluviais observado em Portugal, na União Europeia e nos Estados Unidos da América. Para isso, será efetuada uma análise da legislação, regulamentação, normas e boas práticas desenvolvidas, com 0 intuito de identificar as principais diferenças, vantagens, desvantagens e oportunidades inerentes a cada um. Efetivamente, as águas pluviais têm vindo a apresentar um impacto crescente nos aglomerados urbanos, pelo que este tipo de análise é fundamental para a conceção e implementação de medidas que promovam o desenvolvimento sustentável dos centros urbanos e das regiões envolventes.

\section{2 Águas pluviais: enquadramento estratégico}

\subsection{O percurso dos Estados Unidos da América}

Desde muito cedo que os Estados Unidos da América (EUA) tomaram consciência da importância crescente que a água tem no ambiente e nas sociedades futuras.

Ainda no final do século XIX, foi lançado o primeiro documento legislador, referente à proteção ambiental dos diferentes recursos hídricos. The Rivers and Harbors Act foi promulgado pelo Congresso e assinado pelo Presidente William McKinley, em 1899, tendo como principal foco a proteção da navegação e o combate à poluição das águas. Mais tarde, em 1948, foi aprovado um outro documento - The Federal Water Pollution Control Act -, que visava aumentar, ainda mais, o controlo e a fiscalização dos poluentes lançados nos cursos de água.

Sentindo-se uma maior consciencialização e uma atenção crescente por parte de toda a sociedade americana no que se refere a esta temática, em 1972 deu-se mais um passo no sentido de proteger e aumentar o controlo da poluição aquífera, com a promulgação da lei geralmente conhecida por Clean Water Act - CWA (Copeland 2016). Neste âmbito importa realçar que, apesar de ter sofrido algumas alterações desde então, o CWA desempenhou um papel estratégico, tendo estabelecido os princípios basilares referentes à proteção da qualidade das águas.

Atualmente, o quadro legal norte-americano dispõe de uma grande variedade de normas, instrumentos e ferramentas de regulação, permitindo alcançar o objetivo mais amplo de restaurar e manter a integridade biológica, química e física das águas, prevenir e combater possíveis fontes de poluição, providenciar apoio na melhoria das estações de tratamento das águas residuais e lutar pela manutenção da integridade das zonas envolventes aos diversos cursos de água (EPA 2002).

De forma a controlar melhor as fontes de poluição pontuais, foi criado pelo governo federal e enquadrado no CWA, em 1972, o National Pollutant Discharge Elimination System (NPDES), programa responsável pelo licenciamento e emissão de autorizações para as mais diversas indústrias e instalações que apresentem descargas diretamente para águas superficiais, melhorando, deste modo, a qualidade das águas, através do estabelecimento de limites às concentrações de poluentes presentes nas emissões em causa.

Conscientes de que o problema da poluição não podia ser analisado tendo apenas em consideração as fontes pontuais, a 4 de fevereiro de 1987, foi dado outro importante passo para a sustentabilidade ambiental, quando o Congresso promulgou o Water Quality Act. Esta lei trouxe consigo a adoção de um conjunto de normas e de valoreslimite referentes aos padrões de poluentes tóxicos permitidos nas respetivas massas de águas. 
Paralelamente à aprovação destas leis, e tendo em consideração que não havia ainda uma uniformização dos critérios em todos os Estados, foi também produzido um conjunto de regulamentos, guias e normas, por parte da EPA, de forma a uniformizar todos os procedimentos, permitindo, assim, um combate mais eficaz às emissões de poluentes, bem como a salvaguarda da qualidade e o respeito pelos valores-limite estabelecidos para os agentes poluentes.

Foi de igual modo aprovada, em Congresso, no ano de 1974, a lei The Safe Drinking Water Act (SDWA), com o intuito principal de aplicar medidas de prevenção e de proteção da saúde pública, através da regulamentação do fornecimento de água para consumo humano (EPA 2004).

Como se pode observar, para além de existir uma grande quantidade de informação e uma elevada preocupação com os diferentes tipos de água, a regulamentação e a legislação vigente nos EUA são extremamente abrangentes e completas. Existem múltiplos documentos legais que permitem controlar e proteger os diversos tipos de águas existentes.

No entanto, o quadro legal nesta matéria não se fica por aqui. De forma a controlar todo este processo, está definido em lei que a maioria das descargas de águas pluviais são consideradas fontes pontuais e, como tal, requerem cobertura de uma licença do NPDES. A implementação deste programa é feita, na maioria dos casos, pelas entidades governamentais dos estados em causa. Nos estados e territórios onde ainda não foi dada permissão, o controlo é feito pela EPA.

Assim, o NPDES Stormwater Program é responsável pelas autorizações para descargas de águas pluviais provenientes de três grandes fontes: sistemas municipais de águas pluviais (MS4), atividades de construção e atividades industriais.

Em relação às duas últimas, o controlo e a fiscalização são relativamente fáceis de fazer por parte das autoridades. Por outro lado, o primeiro ponto apresenta dificuldades acrescidas, dada toda a sua dimensão, seja no que se refere aos caudais, seja relativamente aos níveis de poluição.

Tradicionalmente, o que se verificava neste setor era que a maior parte destas águas eram transportadas através do sistema municipal existente, sendo, depois, descarregadas no rio, sem qualquer tipo de tratamento. Nesse sentido e de forma a melhorar a sua qualidade, conjuntamente com a obrigação de todos estes sistemas terem de apresentar uma autorização por parte do NPDES, a EPA publicou, a 16 de novembro de 1990, um conjunto de aplicações e de requerimentos específicos. A abordagem estava, nesta fase, focalizada nas águas pluviais com maior impacto negativo no meio ambiente, nomeadamente, as associadas a atividades industriais $\mathrm{e}$ descargas de águas pluviais provenientes de sistemas municipais referentes a núcleos urbanos com 100 mil ou mais habitantes (EPA 1996).

Mais tarde, em 7 de agosto de 1995, a EPA promulgou a aplicação dos regulamentos relativos à segunda fase do NPDES Stormwater Program. Apenas ficando de fora os que já estavam abrangidos pela primeira fase, estabelecia-se, agora, uma sequência de processos para todos os descarregadores de águas pluviais, nomeadamente para os sistemas de águas pluviais das pequenas localidades, instalações comerciais e institucionais (EPA 1996). Cada sistema de drenagem de águas residuais passou então a ter de desenvolver e de implementar um programa de gestão de águas pluviais, tendo em vista a redução da contaminação das águas e a proibição das descargas ilícitas.

Nos anos seguintes, a aposta neste setor manteve-se, tendo sido publicado, em outubro de 2000, o The National Menu of Best Management Practices for Stormwater Phase II, composto por um conjunto de guias de boas práticas a serem implementadas pelos cidadãos, pretendendo dar informações relativamente a seis grandes grupos ou áreas: 
educação pública, envolvimento público, deteção e eliminação de descargas ilegais, construção, pós-construção e prevenção da poluição.

Com estas normas, regulamentos e legislação, bem como com uma efetiva fiscalização, os Estados Unidos da América pretendem, e têm vindo a conseguir, reduzir significativamente os níveis de poluição das águas pluviais. No entanto, este é um trabalho de melhoria contínua, sendo por isso espectável que, no futuro, surjam novas investigações e soluções de tratamento mais eficientes, acompanhadas por uma gestão e controlo cada vez mais completa.

\subsection{A Experiência na União Europeia}

Nas últimas décadas, assistiu-se a uma crescente consciencialização por parte da sociedade europeia no que diz respeito à importância que os recursos hídricos apresentam nos mais diversos setores de atividade. Considerando que não havia um quadro comum a todos os Estados-membros da atual União Europeia, sentiu-se a necessidade de se elaborar um plano estratégico global, que permitisse uma maior proteção e promovesse o uso eficiente de todos os tipos de água.

Desta forma, e analisando o enquadramento geral e comum a todos os Estadosmembros, "A Comissão Europeia apresentou, em 1994, uma Proposta de Diretiva relativa à qualidade ecológica das águas, que visava desenvolver e aplicar as conclusões do Seminário Ministerial sobre a Política da Água na Comunidade, realizado em Frankfurt, em 1988, nomeadamente, no que se refere ao consenso sobre a necessidade de legislação comunitária a integrar a qualidade ecológica das águas" (AR 2005).

Estes documentos legisladores tiveram um efeito direto na redução das cargas poluentes ao longo dos anos subsequentes, com resultados positivos na qualidade das águas. No entanto, verificou-se também que era necessário alargar o espectro de valores-limite de emissão, parâmetros, indicadores e tipos de água monitorizados (EEA 2018).

Decorrente desse processo, a Comissão Europeia apresentou, em junho de 1997, a Diretiva Quadro da Água (DQA), na qual se estabelece a necessidade de uma maior integração dos aspetos qualitativos e quantitativos para uma gestão sustentável dos ecossistemas aquáticos. Deste modo, é possível uma maior ligação entre as diferentes iniciativas a aplicar pelos Estados-membros, com vista a uma melhoria da proteção dos meios hídricos da Comunidade, valorizando-se o uso sustentável da água, a proteção dos ecossistemas aquáticos, terrestres e zonas húmidas diretamente associados.

Esta Diretiva viria, mais tarde, em setembro de 2000, a ser aprovada pelo Conselho e pelo Parlamento no Europeu, tendo sido publicada no Jornal Oficial das Comunidades Europeias em dezembro do mesmo ano. Trata-se de uma medida que representa um salto qualitativo na abordagem do problema a nível europeu, uma vez que a DQA introduz diversos princípios e aspetos a serem aplicados pelos Estados-membros, dos quais se destacam: avaliação do estado da água, através de uma abordagem ecológica; planeamento integrado a nível da bacia hidrográfica; estratégia para a eliminação da poluição causada por substâncias perigosas; e incremento da divulgação da informação e incentivo da participação do público.

Assim, a partir da análise estrutural da DQA (2000/60/CE), concluiu-se que esta apresenta como objetivo geral o estabelecimento de "um enquadramento para a proteção das águas de superfície interiores, das águas de transição, das águas costeiras e das águas subterrâneas" (PECUE 2000), permitindo reduzir, continuamente, a degradação, melhorar a proteção dos ecossistemas e dos meios aquáticos, promover um consumo de água sustentável, assegurar a redução gradual da poluição das águas subterrâneas e tentar mitigar, ao máximo, os efeitos das inundações e secas. 
Ainda na DQA, é importante salientar o Anexo $\mathrm{VI}$, onde se apresenta uma lista de outras diretivas com grande impacto na qualidade das águas. Destacam-se a Diretiva relativa à qualidade das águas balneares (76/160/CEE); a Diretiva relativa às águas destinadas a consumo humano (80/778/CEE), alterada pela Diretiva 98/83/CE; e a Diretiva relativa ao tratamento das águas residuais urbanas (91/271/CEE), posteriormente alterada pela Diretiva 98/15/CE e pelo Regulamento (CE) n. ${ }^{\circ}$ 1882/2003.

Para além da DQA, que tem um caráter mais global, existe também um conjunto de diretivas mais específicas para as águas de abastecimento, residuais e balneares, que garante um maior controlo sobre as mesmas.

Importa ainda destacar a Diretiva 2007/60/CE, também conhecida por Diretiva das Inundação, que apresenta como grande objetivo o estabelecimento de um quadro geral para a avaliação e gestão dos riscos de inundações, a fim de reduzir as consequências associadas às inundações nas comunidades envolventes, nomeadamente no que concerne à saúde humana, ao ambiente, ao património cultural e às atividades económicas (PECUE 2007). Esta diretiva tem tido um impacto bastante positivo nas regiões, contribuindo para uma gestão mais integrada deste recurso.

Simultaneamente, observa-se também que, em muitos casos, os Estados-membros têm legislação, regulamentação e normas internas, desenvolvidas a diferentes níveis e com o objetivo de fazer face às especificidades e características próprias.

No entanto, analisando apenas iniciativas desenvolvidas a nível macro europeu e comuns a todos, é possível observar que não existe grande trabalho desenvolvido no que concerne à gestão das águas pluviais. Apenas se verifica a possibilidade de, em determinadas condições e situações específicas, estas águas poderem ser inseridas em documentos legais e instrumentos de gestão gerais.

\section{3 caso Português}

O principal instrumento de gestão das águas em Portugal está assente na DQA. É neste contexto que, em 2005, surge a Lei $n .^{\circ} 58 / 2005$, de 29 de dezembro, também conhecida como Lei da Água, onde se transpõe para a ordem jurídica nacional a Diretiva Quadro da Água, estabelecendo as bases do quadro institucional para a gestão sustentável das águas, a nível nacional.

Não obstante apresentar um conjunto de princípios muito idêntico aos da DQA, a lei portuguesa destaca-se pelo acréscimo de um leque de informações e de critérios específicos a aplicar no nosso território. O objetivo primordial passa por estabelecer um "enquadramento para a gestão das águas superficiais, designadamente das águas interiores, de transição e costeiras, e das águas subterrâneas" (AR 2005).

Este documento tem o objetivo de evitar a contínua degradação, proteger e melhorar o estado dos ecossistemas e meios aquáticos, promover uma utilização sustentável da água, assegurar uma redução gradual da poluição das águas subterrâneas, mitigar os efeitos das inundações e das secas, assegurar o fornecimento em quantidade suficiente de água de origem superficial e subterrânea de boa qualidade, conforme necessário para uma utilização sustentável, equilibrada e equitativa da água, proteger as águas marinhas e assegurar o cumprimento dos objetivos dos acordos internacionais.

Merece também destaque o facto de este documento apresentar um conjunto de princípios muito concretos e de elevada importância para a gestão, valorização e sensibilização dos recursos hídricos nacionais. Neste âmbito, nota para o facto de que, em Portugal, a região hidrográfica assume-se como a principal unidade de planeamento e gestão das águas, tendo esta por base uma ou mais bacias hidrográficas.

Paralelamente à Lei da Água, ao nível do planeamento e gestão, merece também referência os seguintes planos, da competência da Agência Portuguesa do Ambiente I. P. 
(APA): o Plano Nacional da Água (PNA), de âmbito territorial e comum a todo o território; os Planos de Gestão de Região Hidrográfica (PGHR), que abrangem as bacias hidrográficas e as águas costeiras integradas numa região hidrográfica e constituem a base de suporte à gestão, à proteção e à valorização social e económica das águas; e os Planos Específicos de Gestão de Águas, complementares aos planos de gestão das regiões hidrográficas.

Em linha com esta legislação e com estes planos, merece também destaque a Convenção Luso-Espanhola. Conscientes do facto de partilharem um grande número de recursos hídricos, realizou-se, a 30 de novembro de 1998, uma convenção sobre a cooperação para a proteção e para o aproveitamento sustentável das águas das bacias hidrográficas luso-espanholas. Deste encontro, resultou um protocolo que entrou em vigor a 17 de janeiro de 2000, tendo sido mais tarde revisto através da Resolução da Assembleia da República n. ${ }^{\circ}$ 62/2008, de 14 de novembro.

Desta forma, e conjuntamente com a Lei da Água, estes documentos visam promover uma gestão eficaz, fornecendo informações importantes sobre o modo como devemos encarar e abordar a utilização deste recurso. Acontece, porém, que, apesar de termos um conjunto assinalável de documentos legais e de instrumentos de gestão para a grande maioria dos tipos de águas, existem ainda algumas falhas que devem ser colmatadas, sob pena de prejudicarem as restantes políticas.

Constata-se, por exemplo, a existência de um Plano Estratégico de Abastecimento de Água e de Saneamento de Águas Residuais (PEAASAR I, 2000-2006), revisto (PEAASAR II, 2007-2013) e atualizado, mais tarde, para Plano Estratégico Nacional para os Sistemas de Abastecimento de Água e de Águas Residuais (PENSAAR 2020), no qual se definem as grandes metas e orientações estratégicas para o setor (APA 2015).

No entanto, a regulamentação existente, no que se refere às águas pluviais, é manifestamente reduzida quando comparada com os restantes tipos de água. Não obstante a sua importância redobrada no contexto da qualidade da água, a verdade é que, à imagem do que acontece na restante legislação europeia, nomeadamente na DQA, a drenagem e a descarga de águas pluviais carece de regulamentação específica.

As referências, na sua grande maioria, são encontradas no Decreto Regulamentar n. ${ }^{\circ}$ 23/95, de 23 de agosto, e no Decreto-Lei n. ${ }^{\circ}$ 382/99, de 22 de setembro. O DR 23/95 concentra, num mesmo texto legislativo, os princípios gerais aprovados pelo Decreto-Lei n. ${ }^{\circ} 207 / 94$, de 6 de agosto, tendo como objetivo assegurar o bom funcionamento global, a segurança, a saúde pública e o conforto dos utentes dos sistemas de distribuição pública predial de água e de drenagem pública e predial de águas residuais (MOPTC 1995). O DL 382/99 estabelece as normas e os critérios para a delimitação de perímetros de proteção de captações de águas subterrâneas destinadas ao abastecimento público, com a finalidade de proteger a qualidade das águas dessas captações (MAOT 2010).

Quanto ao primeiro, as águas pluviais são mencionadas em dois contextos distintos. Em primeiro lugar, no Artigo $114 .^{\circ}$, alusivo aos sistemas de drenagem pública de águas residuais - "Este título refere-se aos sistemas de drenagem pública de águas residuais domésticas, industriais e pluviais e ainda aos sistemas de drenagem privados contemplando fundamentalmente a rede de coletores e o destino final dos efluentes" (MOPTC 1995). Em segundo lugar, quando aborda a questão dos sistemas separativos, para águas pluviais e residuais, referindo que estes sistemas deverão passar a ser implementados, quer na conceção de novos sistemas de drenagem pública de águas residuais, quer na requalificação dos sistemas unitários ou mistos existentes (MOPTC 1995).

Em relação ao segundo, apenas refere que "Os perímetros de proteção das captações de águas subterrâneas destinadas ao abastecimento público visam, assim: Prevenir, reduzir e controlar a poluição das águas subterrâneas por infiltração de águas pluviais 
lixiviantes e de águas excedentes de rega e de lavagens; Potenciar os processos naturais de diluição e de autodepuração das águas subterrâneas; Prevenir, reduzir e controlar as descargas acidentais de poluentes; Proporcionar a criação de sistemas de aviso e alerta para a proteção dos sistemas de abastecimento de água com origem nas captações de águas subterrâneas, em situações de poluição acidental dessas águas" (MA 1999).

Denota-se, por isso, uma diferença substancial na legislação existente para as águas pluviais em relação às águas de abastecimento e residuais. Neste contexto, e apesar destas começarem, gradualmente, a ganhar um maior destaque, torna-se cada vez mais urgente desenvolver planos de gestão holísticos e transversais bem como legislação e regulamentação mais eficaz no sentido de garantir um controlo e uma sustentabilidade maior neste setor.

\section{Conclusões e notas finais}

No decorrer da análise realizada, foi possível observar que a definição de regulamentação para a gestão da água é fundamental para a preservação e proteção do ambiente. Neste contexto, dos principais instrumentos desenvolvidos, nomeadamente 0 Clean Water Act nos Estados Unidos da América e a DQA na União Europeia, na qual se encontra ancorada a legislação portuguesa, resultaram melhorias efetivas na gestão e na qualidade das águas e ecossistemas envolventes.

A legislação e regulamentação europeia e norte americana apresentam algumas semelhanças, mas também algumas diferenças significativas. Atualmente, ambas possuem um plano geral abrangendo a regulamentação de diversos tipos de águas, assente em princípios como os do controlo à poluição, preservação dos ecossistemas e promoção do uso eficiente da mesma. Este enquadramento geral é, depois, adaptado em cada país, no caso da União Europeia, e em cada estado, no caso dos Estados Unidos da América, sendo estes os principais responsáveis pela implementação, controlo e fiscalização das medidas e soluções a serem colocadas em prática.

Nesse sentido, na Europa, cada país é responsável pela qualidade da água do seu território, tendo prazos definidos para o cumprimento de um vasto conjunto de metas ambientais. Portugal não foge à regra, tendo como principal instrumento de gestão a Lei da Água. Esta define e apresenta um conjunto de planos e metas referentes a todo o território. Trata-se de um modelo de ação que, aliás, está em sintonia com o que acontece nos Estados Unidos da América, que também apresentam uma entidade responsável pela criação de planos de ação e de sistemas de controlo e tratamento dos mais diversos tipos de águas - a EPA.

No entanto, importa sublinhar uma diferença assinalável entre ambos. Ao contrário do que se verifica nos Estados Unidos da América, onde já foram implementados múltiplos programas e existe uma sólida legislação, tanto na União Europeia como a nível nacional observa-se uma ausência de regulamentação eficaz no que diz respeito ao controlo e gestão das águas pluviais. Esta é, como tal, uma situação grave, potencialmente geradora de problemas, dado que as águas pluviais se assumem, cada vez mais, como um centro de oportunidades, gerador de melhorias na qualidade de vida das populações, mas, também, como um foco de ameaças, caso não se atue no sentido de fomentar a implementação de estratégias de atuação transversais.

Neste contexto, a conceção e desenvolvimento de instrumentos legisladores, bem como a operacionalização de planos de gestão integrados, poderá assumir-se como uma mais valia para as populações, contribuindo para uma maior sustentabilidade das regiões.

Paralelamente, a definição de valores-limite de emissão para os diferentes agentes poluentes, associado a um controlo e monitorização mais eficaz, é premissa fundamental 
para que se possa efetuar uma melhor gestão deste recurso, salvaguardando, assim, as características ecológicas dos meios recetores.

Sendo clara a importância social, económica e ambiental que a água desempenha, a adoção de uma visão integrada, holística e global para a gestão deste recurso, é, mais do que uma necessidade, uma obrigação das sociedades atuais, no sentido de salvaguardar o desenvolvimento sustentável e promover a melhoria da qualidade de vida das gerações presentes e futuras.

\section{Referências}

APA (2015). PENSAAR 2020 Uma nova Estratégia para o Setor de Abastecimento de Água e Saneamento de Águas Residuais. APA, Lisboa.

AR (2005). Lei N. ${ }^{\circ}$ 58/2005 [Lei da Água] de 29 de dezembro de 2005. Diário da República - I Série-A, N. ${ }^{\circ} 249$, de 29 de dezembro de 2005, Lisboa.

Barbosa A., Fernandes J., David L. (2012). Key issues for sustainable urban stormwater management. Water Research 46 (20) 6787-98.

Burian S., Pitt R., Field R. (1999). Historical Development of WET-Weather Flow Management. Journal of Water Resources Planning and Management 9496.

CE (2013). Compreender as Políticas da União Europeia Europa 2020: a Estratégia Europeia de Crescimento. Serviço das Publicações da União Europeia, Luxemburgo.

Copeland Claudia (2016). Clean Water Act: A Summary of the Law. Congressional Research Service, Washington, D.C.

EEA (2018). European Waters Assessment of Status and Pressures 2018. European Environment Agency, Copenhagen.

EPA (1996). Overview of The Storm Water Program. US Environmental Protection Agency, Washington, D.C.

EPA (2002). Federal Water Pollution Control Act (As Amended Through P.L. 107-303, November 27, 2002). US Environmental Protection Agency, Washington, D.C.

EPA (2004). Understanding the Safe Drinking Water Act. US Environmental Protection Agency, Washington, D.C.

Gasperi J., Zgheib S., Cladière M., Rocher V., Moilleron R., Chebbo G. (2012). Priority pollutants in urban stormwater: Part 2 - Case of combined sewers. Water Research 46 (20) 6693-6703.

Howden M. S., Soussana J. F., Tubiello F. N., Chhetri N., Dunlop M., Meinke H. (2007). Adapting agriculture to climate change. Proceedings of the National Academy of Sciences 104 (40) 19691-19696.

Jha A., Bloch R., Lamond J. (2012). Cities and Flooding. A Guide to Integrated Urban Flood Risk Management for the 21st Century. The World Bank, Washington, D.C.

Kummu M., Guillaume J. H. A., de Moel H., Eisner S., Flörke M., Porkka M., Siebert S., Veldkamp T. I. E., Ward P. J. (2016) The world's road to water scarcity: Shortage and stress in the 20th century and pathways towards sustainability. Scientific Reports 638495 .

MA (1999). Decreto-Lei N. ${ }^{\circ} 382 / 99$ de 22 de setembro de 1999. Diário da República - I Série-A, N. ${ }^{\circ}$ 222, de 22 de setembro de 1999, Lisboa.

MAOT (2010). Decreto-Lei N. ${ }^{\circ} 103 / 2010$ de 24 de setembro de 2010. Diário da República, $1 .^{a}$ Série, N. ${ }^{\circ}$ 187, de 24 de setembro de 2010, Lisboa.

Marlow D., Moglia M., Cook S., Beale D. (2013). Towards sustainable urban water management: a critical reassessment. Water Research 47 (20) 7150-7161. 
Meehl G. A., Stocker T. F., Collins W. D., Friedlingstein P., Gaye A. T., Gregory J. M. (2007). Global Climate Projections. Cambridge University Press, Cambridge.

MOPTC (1994). Decreto Lei N. ${ }^{\circ} 207 / 94$ de 6 de agosto. Diário da República - I Série-A, N. ${ }^{181}$ de 6 de agosto de 1994, Lisboa.

MOPTC (1995). Decreto Regulamentar N. 23/95 de 23 de agosto. Diário da República - I Série-B, N. ${ }^{\circ}$ 194, de 23 de agosto de 1995, Lisboa.

PECUE (2000). Directiva 2000/60/CE [Diretiva Quadro da Água] de 23 de outubro de 2000. Jornal Oficial das Comunidades Europeias, Bruxelas.

PECUE (2007). Directiva 2007/60/CE de 23 de Outubro de 2007 relativa à avaliação e gestão dos riscos de inundações. Jornal Oficial da União Europeia, Bruxelas.

Ramísio P. J. (2007). Retenção de Metais Pesados de Escorrências Rodoviárias por Filtração Reactiva. Universidade do Minho - Escola de Engenharia, Braga.

Tarr J. A. (1979). The separate vs. combined sewer problem: a case study in urban technology design choice. Journal of Urban History 5 308-339.

UN WWA Programme (2015). The United Nations World Water Development Report 2015: Water for a Sustainable World. UNESCO, Paris.

WWC (2015). Integrated Water Resource Management: A New Way Forward A Discussion Paper of the World Water Council Task Force on IWRM. World Water Council, Marseille.

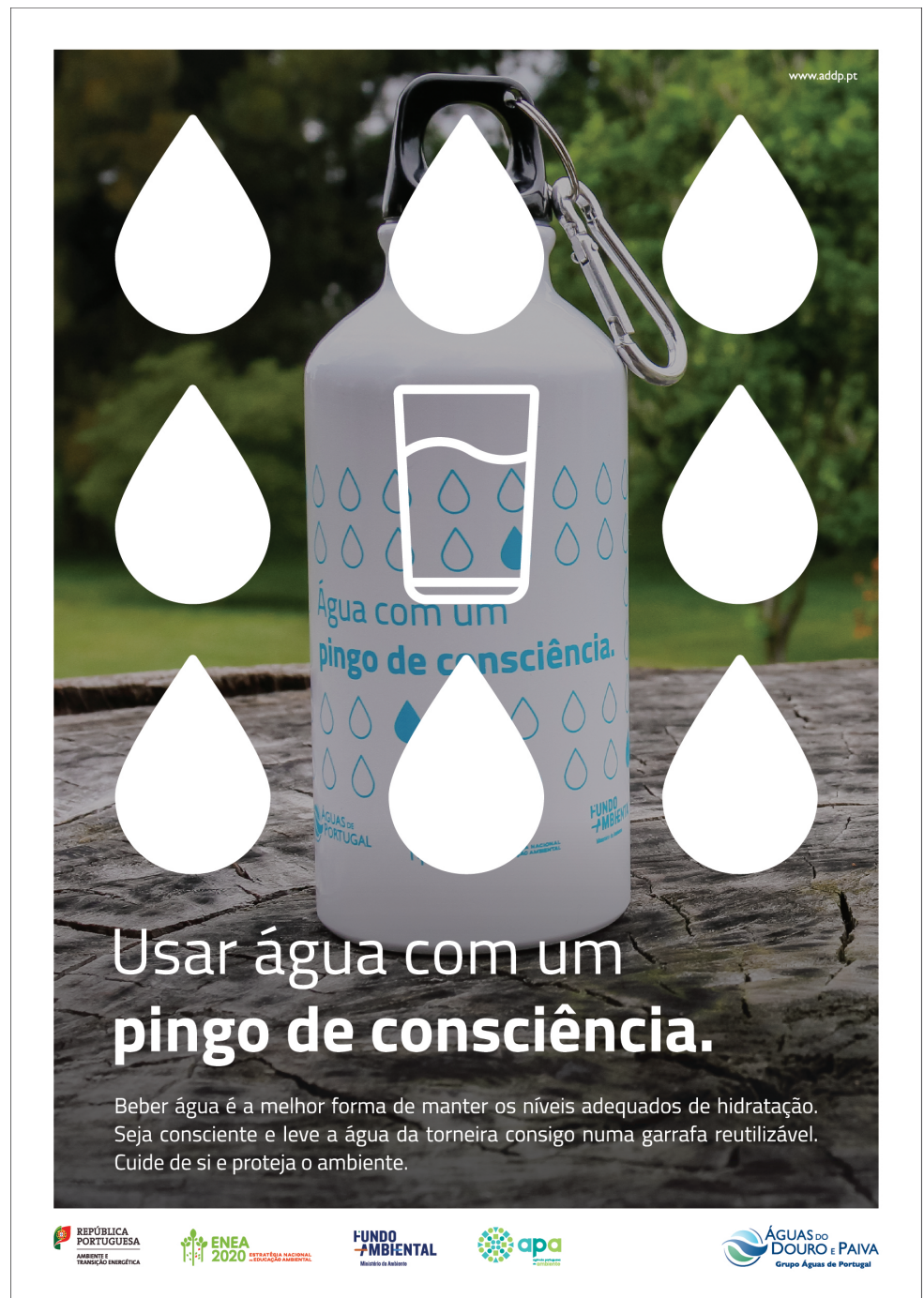

